Correlation Coefficient $0.25, P<0.9, n=6$, two tailed).

Excessively long seizures should be avoided during ECT, partly because of the short acting nature of anaesthetics and muscle relaxants, but also because of the risk of cerebral hypoxia. It is likely that the increased seizure length seen in this patient was due to fluvoxamine. Although there were no serious complications arising from the combined use of ECT and fluvoxamine, a seizure length of 111 seconds is potentially dangerous (Curran \& Freeman, 1995).

CURRAN, S. (1995) Effect of paroxetine on seizure length during electroconvulsive therapy. Acta Psychiatrica Scandinavica, 92, 239-240.

- \& Freeman, C. P. (1995) ECT and drugs. In The ECT Handbook. The Second Report of the Royal College of Psychiatrists' Special Committee on ECT, Council report CR39, (ed. C. P. Freeman), pp. 49-57. London: Royal College of Psychiatrists.

Gutterrez-Esteinou, R. \& Pope, H. G. (1989) Does fluoxetine prolong electrically induced seizures? Convulsive Therapy, 5, 344-348.

ScotT, A. \& Lock, T. (1995) Monitoring seizure activity. In The ECT Handbook. The Second Report of the Royal College of Psychiatrists' Special Committee on ECT, Council report CR39 (ed. C. P. Freeman), pp. 62-66. London: Royal College of Psychiatrists.

\section{Hyde Terrace}

University of Leeds

Leeds LS2 9LT

\section{St James's University Hospital Leeds LS9 7TF}

\section{Suicide prevention versus alcohol promotion}

SIR: Ohberg et al (1996) found that $36 \%$ of suicides in Finland were committed under the influence of alcohol. Although they did not estimate the proportion of those who were dependent on alcohol, it is likely to be high. It is well known that the prevalence of alcoholism is dependent on the per capita consumption. In the UK, the "safe levels" of alcohol consumption were recently increased by $33-50 \%$. It is possible that there will be a proportionate increase in the prevalence of alcohol misuse and dependence and hence the number of suicides. We wonder how this will affect our endeavours to reduce the number of suicides by the year 2000 .

Ohberg, A., Vuori, E., Ojanpera, I., et al (1996) Alcohol and drugs in suicide. British Journal of Psychiatry, 169, 75-80.

J. EWBANK

S. EATON

Addenbrooke's Hospital

A. Michael

Cambridge CB2 $2 Q Q$

\section{Quaker belief and child psychiatry}

SIR: Professor Graham's article on Quaker belief and child psychiatry makes a most valuable contribution to the consideration of the kind of human values which should inform our approach to children and young people in need of care or treatment. This is especially true of chronic, young offenders whom all efforts to help seem to fail and social attitudes become increasingly punitive.

Quaker beliefs and practice might form the basis from which could emerge a suitable therapeutic community approach, offering a quality of care which would do justice to the problems of such desperate and damaged young people.

I feel sure that we can produce a more appropriate response than a British version of the 'boot camp', or the more usual prison or secure accommodation with only minimal therapeutic means at its disposal.

Graham, P. (1996) Quaker belief and child psychiatry. British Journal of Psychiatry 169, 1-5.

66 Old Kennels Lane

W. H. AllChin

Winchester

Hampshire SO22 4TJ 